\title{
Los desarrollistas urbanos y la producción de ciudad. Análisis documental de la especulación en Córdoba
}

\author{
The urban developers and the production of city. A documentary \\ analysis of speculation in Córdoba
}

Erika Saccucci erika sac34@hotmail.com

https://orcid.org/0000-0002-2469-0988

Centro de Estudios Avanzados; Universidad Nacional de Córdoba (Argentina)

\section{Resumen}

Este artículo indaga sobre la dinámica y la importancia de los desarrollistas urbanos, así como sobre el nuevo rol del Estado en materia urbana a partir de la sanción del Plan Director 2020 en Córdoba. Esta nueva normativa no solo modifica las disposiciones sobre el uso del suelo urbano, sino que incluye herramientas de gestión absolutamente novedosas para la Argentina, como las mesas de concertación. De esta manera, a partir de un análisis de fuentes secundarias y documentales, se busca conocer los efectos de estas modificaciones y las 
dinámicas sobre los diversos sectores de la ciudad y la segregación urbana. Se ha concluido que este modo de hacer ciudad ha desplazado al Estado como actor principal de la planificación urbana, y ha puesto en primer plano a las empresas desarrollistas, fomentando la producción de ciudad basada en la especulación y la segregación urbana.

Palabras clave: Capital; especulación; Estado; desarrollistas urbanos; segregación; análisis documental.

\section{Abstract}

The following article inquires about the dynamics and importance of urban developers as well as the new role of the state in urban development since the sanction of the Director Plan 2020. This new law not only modifies the provisions on the use and urban land use, but also includes absolutely innovative management tools for Argentina as public-private concertation. In this way, from an analysis of secondary sources and documentaries, we seek to know the effects of these modifications and the dynamics on the various sectors of the city and urban segregation. It has been concluded that this way of "making city" has displaced the State as the main actor in urban planning, and has put the development companies at the forefront, promoting the production of cities based on speculation and urban segregation.

Keywords: Capital; speculation; state; urban developer; segregation; documentary analysis.

Los años noventa en la Argentina implicaron la continuidad de la implantación del modelo neoliberal, comenzado en 1976 por el gobierno militar. El cambio de modelo productivo significó una reestructuración económica, social y política que abarcaba desde el desmantelamiento de las políticas proteccionistas y centralizadoras, que habían caracterizado al modelo de sustitución de importaciones, hasta la desregulación y el traspaso de funciones sociales del Estado nacional a las provincias.

El proceso de desregulación fomentó el ingreso de grandes capitales internacionales, al mismo tiempo que favoreció la actividad especulativa financiera, por cuanto no existían límites ni restricciones al ingreso y egreso de flujos de capital. Esta reconfiguración implicó una redefinición de las funciones del Estado en todos sus niveles y una nueva dinámica de relacionamiento con las diversas fracciones del capital. Dicha reconfiguración radica, en parte, en la sanción de nuevas legislaciones (1) que redefinieron el rol estatal, incluso en materia urbana. El Estado abandonaba así su función proactiva, como motor principal del desarrollo 
urbano, para convertirse en un planificador a mediano plazo: ello implicó definir zonas estratégicas y habilitarlas para la intervención del capital, que, de ahora en más, sería el nuevo productor de ciudad.

La reestructuración de este modelo abarca la producción de territorialidad, por cuanto la demanda de estos nuevos flujos de capital especulativos-financieros exigía la re funcionalización de las territorialidades configuradas bajo el modelo de producción industrial fordista. El territorio se reconfiguraba de acuerdo con las necesidades de las diversas fracciones del capital (Stratta y Barrera, 2009).

De esta manera, la producción de la territorialidad dejaba de estar ligada exclusivamente al desarrollo de actividades económicas como la industrial y agraria, a la vez que se convertía en objeto y mercancía en sí misma. Se configuraban territorios que importaban un modo de consumir, de ser y de vivir en el espacio. La producción industrial, como forma de generar valor, comenzó a perder su preeminencia en el modo de acumulación neoliberal, para darle lugar a la producción de modos de vida basados en lógicas capitalistas que fundamentan la configuración de una sociedad complejamente diferencial, como la nueva forma de acumulación.

La base para el desarrollo de la actividad inmobiliaria-especulativa en la Argentina fue: la desregulación, el mayor flujo de capitales y el aumento del valor de los commodities. Esto último generó importantes rentas, y buena parte del ahorro de sectores medios y medios altos (que antes de 2001 se dirigía hacia los bancos) comenzó a fluir de manera progresiva hacia los emprendimientos inmobiliarios. Después de la crisis del 2001 ocurrió lo que algunos analistas llamaron una tergiversación de la percepción del riesgo: "Con razón o sin ella, un plazo fijo en una entidad de primera línea internacional era visto como algo menos atractivo y quizás más riesgoso que un boleto de compra venta en un edificio en construcción" (Tabakman, 2006: 34).

En Córdoba, esta tendencia se vio acentuada por la primacía del agronegocio como principal fuente de acumulación económica. La mayor parte del excedente producido por esta actividad económica fue absorbido por el capital inmobiliario. De esta manera, el monocultivo de soja impuesto en el suelo rural de la provincia financia al capital inmobiliario (Ferrero, Ibáñez Mestre y Machado Ibars, 2012). Esto produjo un boom inmobiliario en la ciudad, donde la construcción de edificios de altura desbordó el casco céntrico de la urbe y se trasladó a los sectores periféricos.

A partir de estos cambios estructurales, el mercado inmobiliario se reconfiguró: por un lado, se produjo la fusión de varias empresas constructoras; por el otro, las inversiones se volcaron cada vez más hacia mega emprendimientos urbanos: los countries, es decir, las urbanizaciones o los proyectos inmobiliarios más rentables realizados por los desarrollistas (2). 
Los countries son una de las expresiones más significativas de la fragmentación socio territorial del espacio urbano provocada por el capital inmobiliario. Se caracterizan por la existencia de marcas espaciales que establecen los límites de la urbanización: muros, barreras, garitas de seguridad y cercos de alambres. A través de ellos se privatiza el espacio público. Representan también la pérdida de la significación social de los espacios públicos a través de la apropiación de lugares que previamente eran de uso público (Roitman, 2003). El surgimiento de estas nuevas dinámicas de habitabilidad evidencian la ruptura del tejido social urbano y profundizan cada vez más una ciudad dual, privatista y excluyente (Capdevielle, 2013).

Estos nuevos barrios cerrados, producidos por actores privados, fueron acompañados por un cambio en la normativa del uso del suelo, a partir de la Ordenanza 8606/91 de la Municipalidad de Córdoba. Esta denominó a los countries como urbanización residencial especial, y mediante el concepto de áreas especiales les otorgó la posibilidad de negociar excepciones de las normas en terrenos de grandes dimensiones (Capdevielle, 2013). De esta manera, el Estado municipal generaba el marco normativo jurídico para favorecer la reproducción del capital inmobiliario $y$, por ende, la creación de nuevos countries; hecho que se mantiene en la actualidad (3).

Cuando los desarrollistas presentan estas urbanizaciones a sus clientes, no solo están ofreciendo viviendas para habitar, sino una forma de vida: el estilo de vida countrie, esto es, un modelo de vida estandarizado que representa una oferta inmobiliaria que mercantiliza valores ligados a una determinada calidad de vida. Los desarrollistas promueven un discurso en el que la urbanización cerrada se presenta como un ámbito protegido para el desarrollo familiar: esto, a su vez, produce, ante la comparación con el resto del espacio urbano, una dicotomía: el adentro, representado por la seguridad, el orden y lo verde, y el afuera, identificado con el peligro, el caos, lo violento y los gris (Del Cueto y Neuburger, 2009).

Los desarrollistas producen, entonces, determinadas formas de vida que se constituyen como las deseables, basadas en modos de conceptualizar la habitabilidad, la salubridad, el consumo, el uso del espacio, y a partir de una propuesta estética concreta. Todas aquellas formas de vida opuestas serán definidas como no deseables y disputables (Saccucci y Feldmann, 2015).

El capital financiero-inmobiliario configura así territorialidades que, al ser comercializadas, venden mucho más que una porción espacial; incluyen un modo de vivir, una pertenencia de clase y un estatus social. La ciudad se reconfigura a partir de la producción de territorialidades basadas en un criterio de diferenciación y jerarquización social. Se deriva así que el capital inmobiliario-financiero no solo produce unidades habitacionales, sino que gestiona la vida de la población, al construir lógicas de vida mercantilizadas, sustentadas en la configuración de nuevas relaciones sociales ancladas a crecientes procesos de heterogeneización que buscan

Question, Vol. 1, N. ${ }^{\circ}$ 63, julio-septiembre 2019. ISSN 1669-6581

Instituto de Investigaciones en Comunicación | Facultad de Periodismo y Comunicación Social | Universidad Nacional de La Plata La Plata | Buenos Aires | Argentina

Página 4 de 18 
acentuar las diferencias entre los sectores sociales. En la actualidad resulta preciso hablar de una ciudad metropolizada, descentralizada y con múltiples centros urbanos, como si se tratase de islas conectadas en la distancia con un circuito de autopistas. El resultado es, una ciudad altamente segmentada que persigue la acentuación de dicha diferencia (Amándola, 2000).

La aparición de los countries profundizó la mercantilización del suelo urbano y consolidó el modelo de ciudad privatista y excluyente para grandes sectores de la población. Según la Dirección de Catastro de la ciudad de Córdoba, en 2008 los countries, barrios privados en altura, urbanizaciones rurales y complejos cerrados ocupaban el $28 \%$ de la superficie, mientras que las urbanizaciones tradiciones, un 56\% (Capdevielle, 2013).

\section{Métodos}

Este artículo se vincula con la investigación desarrollada por el colectivo El Llano en Llamas "Territorios en disputa. Un estudio sobre los conflictos territoriales urbanos y rurales en la Provincia de Córdoba", financiada por el Ministerio de Ciencia y Tecnología de Córdoba. Dicho proyecto centraba su atención en la lucha por el acceso a la tierra. Particularmente, para esta investigación se ha desarrollado un análisis documental de un diario de Córdoba. El concepto de análisis documental ha sido tratado por muchos autores y ha evolucionado al ritmo de la documentación. Es posible afirmar que existen dos tendencias respecto a su concepción, una considera que el análisis documental comprende varias fases, y la descripción bibliográfica es una de ellas, y otra sostiene que el análisis documental debe considerarse exclusivamente como descripción del contenido y no como descripción formal. Este trabajo adscribe a la segunda perspectiva que sostiene que el análisis documental reconoce dos elementos estructurantes: el análisis de de soporte y el análisis de contenido.

A su vez, propone que hay dos niveles de análisis: el externo y el interno. Ambos están en relación directa con la información contenida en el documento y con su soporte. El análisis externo se efectúa sobre el soporte y el interno sobre el contenido que se ocupa del mensaje identificándolo e informando sobre él. De ahí que podamos extraer dos fases: análisis externo o formal y análisis interno o de contenido.

Así, se ha procedido a la recolección de noticias relevantes a la temática investigada, enfocando principalmente en aquellas publicadas en el diario La Voz del Interior. A partir de dicho relevamiento se conformó un corpus donde se priorizó el análisis de contenido. Para ello se diseñó una estrategia de aproximación consistente en varias dimensiones. En un primer momento se procedió a la lectura minuciosa del corpus para luego comenzar a indizar algunos

Question, Vol. 1, N. ${ }^{\circ}$ 63, julio-septiembre 2019. ISSN 1669-6581

Instituto de Investigaciones en Comunicación | Facultad de Periodismo y Comunicación Social | Universidad Nacional de La Plata La Plata | Buenos Aires | Argentina

Página 5 de 18 
elementos discursivos que pudiesen estar advirtiendo sobre posibles relaciones entre las noticias.

La técnica de análisis de contenido implica la lectura general de toda la documentación, su posterior segmentación y la indización de aquellos extractos sugerentes. Luego, se procedió a releer estas selecciones para identificar los aspectos característicos que denotaban.

Las noticias fueron relevadas del diario La Voz del Interior ya que este es uno de los de mayor importancia del interior del país, el de mayor tirada de la provincia y su frecuencia es diaria.

\title{
La especulación en la ciudad
}

En el contexto descrito aparecen nuevos actores económicos y políticos, protagonistas de estas transformaciones en el espacio urbano: los grupos desarrollistas. Estos difieren de las simples constructoras inmobiliarias, ya que son corporaciones con grandes capacidades operativas que abarcan, en su estructura, todas las etapas productivas, incluso aquellas que están relacionadas con la infraestructura. Son empresas inmobiliarias que por primera vez elaboran proyectos urbanísticos en todas sus modalidades, a la vez que compatibilizan todos los aspectos técnicos, jurídicos, económicos y socio ambientales bajo el principio de asumir el costo y riesgo del resultado del proyecto. Corral y Cuenya señalan al respecto:

\begin{abstract}
Son agentes del mercado inmobiliario que conjugan varios perfiles: detectan el negocio, lo estructuran, consiguen el financiamiento o lo aportan con capital propio, llevan adelante la obra y comercializan el producto final. Son caracterizados como hombres de negocios emprendedores (típicamente arquitectos, ingenieros, brokers inmobiliarios, eventualmente abogados o contadores), con intuición suficiente como para anticipar los cambios urbanos y las tendencias en el mercado, con capital propio o de terceros, con capacidad empresaria, creatividad, convicción y habilidad de negociación (2011: 30).
\end{abstract}

Según la Cámara Empresarial de Desarrollistas Urbanos de Córdoba (CEDUC), los proyectos urbanísticos abarcan un espectro de actividades multidisciplinarias de diversa complejidad, tales como estudio de localización del sitio, estudio de mercado actual e inducido, estudios de potencialidad futura del proyecto, desarrollo del proyecto arquitectónico y económico-financiero (en relación con las inversiones necesarias, económicas y procesales), estudio e instrumentación de los mecanismos de financiamiento en los mercados financieros y de capitales, promoción y comercialización del producto en el proceso de pre- y posventa, y 
promoción de acciones tendientes a la consolidación de los emprendimientos, minimizando los potenciales conflictos en sus distintas etapas: proyecto, desarrollo y explotación.

Este accionar de las empresas desarrollistas resulta novedoso en diversos planos, sobre todo en el económico. De acuerdo con Barreto (1995) el espacio urbano se caracteriza por su heterogeneidad, que viene dada, entre otros elementos, por la diversa calidad en infraestructura, la concentración demográfica y la significación simbólica asociada a cada área urbana. Estas características se presentan como valores de usos diferenciales para las diversas fracciones del capital, que buscan instalarse en aquellas áreas donde se concentran la mayor cantidad de elementos y rasgos necesarios para su máximo desarrollo. Desde esta perspectiva, el capital siempre depende de tales atributos, en la medida en que han sido creados colectivamente y ninguna fracción podría producirlos de manera independiente. Los capitales explotan y se apropian de los beneficios de estas características creadas históricamente.

Ahora bien, la dinámica de los desarrollistas desafía esta explicación, puesto que, por primera vez, un capital se encuentra en condiciones de producir por sí mismo estos atributos. Precisamente, el negocio de esta nueva modalidad de producción es la compra, a muy bajo costo, de grandes porciones de tierra que se encuentran en áreas depreciadas por su mala conectividad, precaria infraestructura y simbólicamente asociadas a zonas pobres o incluso rojas, para invertir luego grandes cantidades de dinero en la producción de complejos habitacionales exclusivos. La renta obtenida de este modo de producir es exorbitante, mucho más elevada que si se tratara de una construcción tradicional en una zona que ya cuente con los atributos necesarios para el desarrollo del emprendimiento, comercializado luego por una empresa inmobiliaria. Al respecto, Corral y Cuenya sostienen:

\begin{abstract}
Uno de los tipos de prácticas especulativas que pueden ponerse en práctica en los grandes proyectos urbanos es ejercido por actores capaces de generar externalidades que inciden en el precio del suelo dentro de ese espacio. Esta especulación es típicamente ejercida por dos tipos de agentes: i) los promotores/desarrolladores que compran el suelo a precios de un uso que arroja rentas moderadas y luego de su acción transformadora venden el espacio construido con los precios que corresponden a ese nuevo uso jerarquizado, es decir, con rentas superiores; ii) el gobierno local, que invierte en obras de infraestructura para acondicionar el suelo y aprueba normativa asignando nuevos usos y coeficientes constructivos (2011: 5).
\end{abstract}

De esta manera, la renta de las desarrollistas asume diversas dimensiones: 
-La adquisición de grandes porciones de tierra a muy bajo costo.

-La capacidad de negociación frente al municipio, por excepciones que los habilitan a una ganancia mayor que aquella que obtendrían si respetasen la legislación.

-La producción de complejos habitacionales exclusivos que no solo comercializan una vivienda, sino que venden modos de vida en términos simbólicos y cuya exclusividad los habilita a cobrar un precio mayor.

-Intervención en todo el proceso productivo, tras lo cual se logra una integración vertical de la producción, que incluye desde la infraestructura hasta la venta y financiación (en caso de que fuese necesaria) de la vivienda.

A diferencia de la dinámica tradicional desarrollada por las diversas fracciones del capital (que operaban sobre una ciudad ya dada y reproducían sus características), las empresas desarrollistas producen ciudad en su sentido más literal, por lo que la ganancia es total. En este sentido, la necesidad de consolidarse como actores de gran relevancia en materia política, para obtener un peso sustantivo frente al municipio, los llevó a crear, en 2004, la Cámara Empresarial de Desarrollistas Urbanos de Córdoba (CEDUC) (4), integrada por 45 miembros y diez socios adherentes. La CEDUC se constituye como un actor colectivo cuyo fin es lograr una acción corporativa que presione al Estado para que brinde las condiciones necesarias para la reproducción del capital inmobiliario.

Esta estrategia de acción política busca, por un lado, legitimar la nueva forma de producción del espacio urbano y, por el otro, aumentar la correlación de fuerzas para negociar con el Estado el control y uso del espacio público. Con ello trata de influir en las normativas que regulan el mercado y los usos y las disposiciones del suelo.

En la actualidad, los emprendimientos inmobiliarios más importantes se encuentran en manos de las empresas desarrollistas. Basan su producción en la especulación en torno al precio de la tierra y de las rentas potenciales, y por ello se constituyen en el único actor interviniente en todo el proceso productivo. Datos de un informe de 2014 de la CEDUC muestran cómo la actividad inmobiliaria hoy es producida por y para los especuladores, y no para los fines de vivienda:

-De contado. Las ventas no financiadas totales durante septiembre fueron superiores en un $83,2 \%$ a las registradas en septiembre de 2013 . Las transacciones de lotes crecieron $196,7 \%$ interanual, y las de departamentos y casas, 15,5\%. En cambio, cayeron las de cocheras en un $26,6 \%$. 
-Financiadas. Las operaciones en septiembre fueron $47,8 \%$ inferiores a las registradas en septiembre de 2013, como consecuencia de menores ventas financiadas tanto de departamentos y casas $(66,3 \%)$ como de cocheras $(75 \%)$ y lotes $(6 \%)$.

De acuerdo con los datos producidos por la CEDUC, publicados en 2014 (comprende el periodo septiembre 2013 a septiembre 2014), se obtienen diversas conclusiones. Una de ellas es que mientras las operaciones de compra financiadas bajaron cerca del $50 \%$, aquellas de contado aumentaron $83 \%$. De esto se desprende la composición social de los compradores; es decir, el sector asalariado, al no poseer capacidad de ahorro suficiente, no puede acceder al financiamiento ofrecido por estas entidades, mientras que el sector que aumentó su compra dispone del capital necesario para realizar las erogaciones de contado. Podría estimarse, al mismo tiempo, que estos últimos son los sectores dinámicos de la economía que realizan la compra a los fines de la especulación inmobiliaria, y no por su valor de uso.

Esta tendencia se mantuvo en los últimos años:

\begin{abstract}
La devaluación del peso terminó generando mejores condiciones comerciales para el sector, ya que el precio de sus productos en ladrillos bajaron de 1.900 a 1.500 dólares el metro cuadrado, lo que generó oportunidades para los inversores. Aquel que apostó a las Lebac (5) perdió con respecto al dólar; es por eso que el inversor está volviendo, sobre todo el comprador vinculado al agro ( La Voz del Interior, 11/12/2018).
\end{abstract}

En términos estructurales, los sectores asalariados y populares no pueden acceder a la vivienda propia por medio de los mecanismos de mercado. Esto se ve reflejado en los datos del último censo de la provincia, donde el déficit habitacional ronda el 50\%, mientras que, para 2010, se registraba un $20 \%$ de viviendas particulares ociosas (El Llano en Llamas, 2013). Por lo tanto, el problema radica en las formas de acceso a la vivienda y en su concentración por el capital a los fines especulativos.

La tierra urbana ha atravesado grandes procesos de revalorización. Desde 2007 hasta 2013, el valor de los terrenos dentro del anillo de la circunvalación subió, en promedio, 10\% por año ( $50 \%$ en cinco años); sin embargo, hay zonas como las de Nueva Córdoba (próxima al centro) que se revalorizaron $18 \%$ anuales ( $87 \%$ en el periodo abarcado) ( $L a$ Voz del Interior, 24/02/2013). Nuevamente, quienes están en condiciones de comprar y especular son los sectores dinámicos del capital, en detrimento de la compra para la vivienda familiar, por lo que la lucha por el acceso a la tierra y a la vivienda digna ha cobrado una singular relevancia en la provincia. 


\section{Se le debe exigir ciudad al privado}

Una de las empresas desarrollistas más importantes de la provincia es Edisur. En 2005 comenzó un proyecto residencial y comercial de 150 hectáreas, Ilamado Manantiales Ciudad Nueva. Actualmente, este cuenta con diez barrios diferentes de acuerdo con distintos estilos de vida y con capacidad para 25.000 residentes. Recientemente ha decidido triplicar su desarrollo: apostó a la zona aledaña a Ruta 5 (camino a Alta Gracia) a través del lanzamiento de un nuevo Manantiales de 330 hectáreas. Este cuenta con capacidad para 60.000 residentes y con 153 lotes desde 1000 metros cuadrados (m2), lo que lo llevará a invertir 700 millones en diez años, solo para terrenos e infraestructura básica de los loteos. En total, el grupo Edisur lleva construidos $75.000 \mathrm{~m} 2$ en nueve proyectos de forma simultánea, además de siete urbanizaciones y countries en la ciudad de Córdoba ( La Voz del Interior, 21/10/2014).

Por lo descrito anteriormente, esta empresa planea producir una ciudad de la envergadura de Alta Gracia (6) en el sureste de la capital cordobesa. De esta manera, la zona sur se encuentra ampliamente atravesada por los proyectos inmobiliarios de esta organización desarrollista, por cuanto el $70 \%$ de ellos se encuentran emplazados allí (7).

Esto reafirma el hecho de que por primera vez surgen grupos empresariales que cuentan con todas las capacidades financieras y operativas necesarias para proyectar y producir nuevas ciudades. Pero en la actualidad los grupos desarrollistas ya no solo tienen la capacidad de ejecutar proyectos propios, sino que ahora han creado una nueva modalidad para reproducir el capital: han empezado a hacerse cargo de la gestión, el desarrollo, la administración y la comercialización de diez proyectos con empresas más pequeñas que ya están en marcha; se autodenominan desarrollistas desarrolladores (La Voz del Interior, 12/09/2018).

La mayoría de estos emprendimientos violan, en su diagramación, las disposiciones de uso del suelo de la ciudad, por la extensión de sus loteos y otros aspectos; sin embargo, estos no podrían realizarse sin el aval y la autorización por parte del municipio de la ciudad de Córdoba. Este aval, a pesar de las irregularidades del proyecto, se fundamenta en una de las tres herramientas del Plan Director 2020:

El Plan prevé tres tipos de herramientas destinadas a intervenir sobre las territorialidades: las directas, donde el municipio se hace presente en determinado espacio a través, por ejemplo, de obras públicas propias o incluso de acuerdo con otros niveles de gobierno. Las indirectas, que están relacionadas con la sanción de normativas relativas al uso y disposiciones de la tierra; y las mixtas, que son aquellas que proponen la articulación con privados (p. 17).

Question, Vol. 1, N. ${ }^{\circ} 63$, julio-septiembre 2019. ISSN 1669-6581

Instituto de Investigaciones en Comunicación | Facultad de Periodismo y Comunicación Social | Universidad Nacional de La Plata La Plata | Buenos Aires | Argentina

Página 10 de 18 
A esta última herramienta se le ha denominado concertaciones público-privadas (8), a través de las que pueden captarse las plusvalías generadas por la inversión de grandes capitales en el mercado inmobiliario; tales montos son destinados al desarrollo de la ciudad. Asimismo, se prevé la posibilidad de plantear proyectos co-gestionados entre la Municipalidad y el sector privado, a fines de producir y comercializar tierra urbana para diferentes sectores sociales ( $\mathrm{La}$ Voz del Interior, 21/10/2014). De esta manera, las concertaciones tienen una finalidad concreta:

\begin{abstract}
Alinear los intereses entre ambos sectores, de manera tal que, primando el interés público sobre los particulares, facilite a estos, respetando dicha premisa, motivar actos administrativos que permitan concertar acciones que faciliten la ejecución de obras y proyectos (Grupo Edisur, 2008).
\end{abstract}

En otras palabras, las mesas de concertación funcionan como espacios de negociación entre el municipio y los privados para conseguir excepciones a las normas establecidas, con el fin de poder llevar adelante proyectos edilicios a cambio de realizar obras públicas: "La Municipalidad de Córdoba insistirá en el uso de las concertaciones público-privadas para conseguir obras a cambio de excepciones en la normativa. Se podrán ejecutar en zonas a desarrollar determinadas por el Plan Director" (La Voz del Interior, 16/02/2012). Cabe mencionar que en los últimos siete años se han firmado más de 20 convenios, de los cuales la ciudad obtuvo obras de pavimentación (9), lotes, materiales y pintura de postes de alumbrado, entre otros aportes. A cambio, se autorizaron negocios inmobiliarios en 1.741 hectáreas, con beneficios para los privados muy superiores a las compensaciones. La totalidad de estos acuerdos fueron aprobados en tiempo record ( La Voz del Interior, 9/12/2018).

La aplicación de esta dinámica como la privilegiada a la hora de producir ciudad se basa en un desplazamiento del municipio como el ejecutor exclusivo de la obra pública. Este fenómeno es conceptualizado por Harvey (2007) como empresarialismo urbano, por cuanto se promueve una alianza entre sector público y sector privado en la que el gobierno local es uno más de los múltiples agentes que intervienen en la escena urbana dominada por la influencia de coaliciones multi agentes y consorcios público-privados. La combinación de recursos privados con capacidades gubernamentales sirve para intentar atraer fuentes de financiamiento externo, nuevas inversiones directas o nuevas fuentes de empleo (Harvey, 2007).

El estado municipal se convierte así en un actor más entre los múltiples que intervienen. Define algunas reglas del juego, proyecciones estratégicas y planes de acción, pero rara vez los desarrolla por sí mismo; por lo tanto, el plan funciona como herramienta que persigue el 
objetivo de aunar capacidades hoy dispersas, esto es, aquellas provenientes del sector privado, a partir de la puesta en práctica de las denominadas mesas de concertación.

Resulta interesante indagar sobre las nociones de desarrollo de la ciudad y necesidades que construye la práctica de gobierno, cuando el Estado direcciona dividendos que tienen origen y finalidad privada. Cabe preguntarse: ¿De qué manera la concertación con privados paliaría necesidades en diversos espacios? ¿A qué se hace referencia cuando se habla de necesidades? Una respuesta posible podría estar dada por quienes integran estas mesas de concertación; en ellas participan diversos actores privados, sobre todo cámaras empresariales inmobiliarias y aquellos actores denominados grupos desarrollistas.

En estas mesas se acuerdan y garantizan mega emprendimientos en materia inmobiliaria, se definen las funciones de cada parte presente y se negocian las zonas de desarrollo del emprendimiento (dentro de los polígonos que señala el Plan Director 2020). En muchos casos, el desarrollista asume la construcción de infraestructura que, en términos formales, le correspondería al municipio. Uno de los ejemplos de este mecanismo es la concertación entre Edisur y el municipio de Córdoba:

Esta generó un acuerdo original que prevé que el municipio autorice a Edisur a construir tres barrios abiertos en áreas donde ya tenía autorizados tres countries, a cambio de inversiones privadas por 10 millones de pesos en infraestructura vial. A eso se le suman ahora dos dispensarios de casi 200 metros cuadrados cada uno por un costo de 900 mil pesos. Edisur ya aceptó ese nuevo cargo en una adenda al convenio ( La Voz del Interior, 19/09/2008)

A cambio de la excepción que le habilita el municipio a los fines de poder desarrollar el emprendimiento Manantiales, la empresa desarrollista realizó diversas obras como la extensión de avenida Cruz Roja y la avenida Circunvalación. Cabe aclarar que dichas obras benefician a la desarrollista, pues permiten la conexión con otro de sus grandes emprendimientos recientes: Cascada Country Golf. Además, fruto de esa misma concertación, el municipio negoció con el desarrollista la construcción de dos dispensarios en los barrios Las Flores y Parque República. Una de las acciones que posibilitaba esta concertación era la modificación del cauce del Canal Maestro: se generaba una contención que beneficiaba al complejo Manantiales; sin embargo, recientemente vecinos del asentamiento Costa Canal han denunciado la pérdida de sus viviendas, al desmoronarse por inundaciones generadas por esta alteración (Día a día, 23/02/2015). De esta manera, la panacea de que estos mecanismos redundarían en un beneficio social, al desarrollar ciudad y refuncionalizarla -incluyendo la socialización de la 
obra "pública"-, muestra su cara más cruda cuando priman los intereses privados por encima de los sectores excluidos y se (re)produce una ciudad segmentada y excluyente.

Otro ejemplo de concertaciones realizadas es el acuerdo entre Gama y la Municipalidad para realizar los trabajos en el Teatro Comedia. Las obras, por 16 millones de pesos, se ejecutarán con fondos de excepciones. El grueso de los fondos provendría de Gama, que ya aportó por la obra de 15 torres de departamentos que se construirán en la avenida Colón al 4500.

Según lo anteriormente dicho, es necesario reproblematizar las funciones y los roles del Estado en torno al diseño y la ejecución de las políticas públicas. A partir del surgimiento de la figura de los desarrollistas urbanos, el municipio recurre a tercerizar el financiamiento de la obra pública a cambio de posibilitar excepciones. Estas favorecen la actividad especulativa dentro de zonas previamente diagnosticadas y delimitadas, al punto tal que incluso la inversión en materia de salud pública (construcción de dispensario en barrios populares) quedaría supeditada al cálculo de plusvalía del desarrollista urbano y la renta estimada y especulada de su inversión. En contrapartida, con base en dicho cálculo, el municipio propone obras públicas financiadas por el sector privado.

De esta manera, las concertaciones, vistas desde la perspectiva de los desarrollistas, pueden asumir dos formas, cada una ligada a un objetivo y un beneficio: por un lado, aquella que se basa en desarrollar obras que están por fuera del propio plan de la desarrollista, pero el cual, sin embargo, genera consenso social en torno a su figura como productor de ciudad; por otro, aquella que se focaliza en producir infraestructura que a simple vista apuntaría a generar mejorías urbanas, pero que, de alguna manera, están relacionadas con el proyecto inicial de la desarrollista. En otras palabras, benefician al emprendimiento, al revaluar sus instalaciones dadas estas inversiones; por ejemplo, las obras en materia vial citadas anteriormente, que mejoran el acceso al predio a través de nuevas conectividades.

Podemos decir, entonces, que existen dos tipos de inversiones en obras públicas por parte de los desarrollistas, de acuerdo a la funcionalidad que cumplan: por un lado, las obras que generarán beneficios directos al emprendimiento y que discursivamente son publicitadas como aportes a la ciudad y a la sociedad (infraestructuras de conectividad, redes cloacales, etc.); por otro lado, las obras, que si bien no generan beneficios económicos en sí mismas, cumplen una función de legitimación, por cuanto el beneficio es indirecto (dispensarios, teatros, centros culturales). 


\section{Reflexiones finales}

El espacio urbano es el resultado de luchas políticas de diversos actores que compiten por los recursos sociales y económicos. Uno de los nuevos actores que adquirieron importancia en los últimos años en esta lucha política son, sin lugar a dudas, los desarrollistas urbanos. Estas corporaciones tienen la novedosa capacidad de producir y planificar verdaderas ciudades por sí solas, mediante megaproyectos de inversiones privadas volcadas al capital inmobiliario.

Los desarrollistas urbanos no solo venden a sus clientes viviendas para habitarlas, sino que producen determinadas formas de vida, estandarizadas y mercantilizadas, que apelan a las ideas de seguridad, orden y naturaleza. Los barrios cerrados funcionan como dispositivos de producción y gestión de la vida social, y con ello profundizan cada vez más la ciudad dualista, fragmentada y excluyente.

Para poder realizar los megaproyectos urbanísticos, los desarrollistas deben negociar con el Estado a través de las concertaciones público-privadas, para que este les otorgue amplias excepciones a las normas urbanísticas vigentes. A cambio de ello, las empresas se comprometen a financiar y realizar obras públicas en diferentes sectores de la ciudad. La puesta en marcha de este nuevo mecanismo de articulación público-privado implica una redefinición y reconfiguración del Estado municipal: sus capacidades, rol, función, proyección y modos de intervenir. Se limita, entonces, a tratar de dirigir el libre desarrollo de las empresas, negociando a cambio obras públicas que deberán ser ejecutadas por los desarrollistas en aquellas zonas señaladas como estratégicas por el Plan Director 2020.

Las obras públicas quedan supeditadas al cálculo de la plusvalía del desarrollista urbano y la renta estimada y especulada de su inversión. De esta manera, en base a dicho cálculo, el municipio propone obras públicas, en tanto el sector privado las financia. La mayoría de estas obras no solo intentan legitimar el discurso de los desarrollistas ante la sociedad, sino que implícitamente forman parte del proyecto en sí mismo y tienen como función revalorizar la zona para incrementar las ganancias del proyecto.

El rol del Estado en torno a la producción de la ciudad en Córdoba profundiza una ciudad cada vez más excluyente, fragmentada y dualista. Para aquellas zonas previamente definidas como estratégicas habrá vía libre para los desarrollistas, a través de excepciones a las normas urbanísticas, concertaciones público-privadas, privatización y mercantilización de los espacios públicos, obras en infraestructuras para revalorización de las inversiones privadas y construcción de un ideario de estatus social. Para aquellas zonas que aún no son consideradas como prioritarias habrá gobernabilidad y control social, políticas sociales focalizadas y dispositivos de seguridad para la contención del descontento social. 
Notas

(1) En Córdoba, un ejemplo de esto es el Plan Director 2020, que regula el uso del suelo. Este programa establece zonas estratégicas dentro del entramado urbano, bajo el nombre de polígonos, donde se promoverán acciones inmobiliarias para evaluarlas. Dicha promoción, en la práctica se ha hecho a través del instrumento de concertaciones público-privadas.

(2) Las Delicias (1991), Lomas de Carolina (1994), Jockey Club (1995) y Valle Escondido (1998) son los barrios privados cerrados más conocidos que empiezan aparecer en las periferias de la ciudad de Córdoba.

(3) En 2014, la reforma del Código Civil y Comercial modificó la regulación hacia los countries, barrios cerrados, barrios privados, clubes de campo, clubes náuticos o condominios, al asimilarlos a una especie particular del régimen de propiedad horizontal. Con ello se les permitió constituirse en asociaciones sin fines de lucro, en lugar de sociedades anónimas. Ello suponía una disminución en las expensas o los gastos comunes, al eximirlos del pago del impuesto de valor agregado (IVA) y del impuesto a las ganancias.

(4) La CEDUC se fundó en 2005 e integra a las empresas constructoras y desarrollistas más relevantes: 3D Desarrollistas, Grupo Arinco, Bruna y Allende Posse Desarrollistas, By Best Developers, Grupo Dinosaurio, Ecipsa, Edilicia Suez, GAMA, GNI, Grupo Betania, Edisur, H. A. Bugliotti Arquitectos, Volterra, entre otros.

(5) Las Letras del Banco Central (LEBAC) son títulos de deuda a corto plazo que licita el Banco Central de la República Argentina (BCRA) con pago total y único al vencimiento (instrumento bullet) y cuyo rendimiento o costo financiero surge de una tasa de descuento implícita para el período en cuestión. Se pueden adquirir sólo con dinero en efectivo a través de bancos o sociedades de bolsa. Existen LEBAC en pesos, en pesos ajustables por CER y en dólares. Fueron creadas en 2002.

(6) De acuerdo a datos del censo provincial de 2008, la ciudad de Alta Gracia posee 46.858 habitantes y ocupa el sexto lugar en relación a población.

(7) La nueva estrategia que ha desarrollado Edisur implica generar vías de conexión interna entre los diversos proyectos inmobiliarios. Un ejemplo de esto es la conexión entre Cascada Country Golf y el Complejo Manantiales. El primero tiene una extensión de 120 hectáreas, divididas en un total de 261 parcelas. Cada terreno tiene una superficie de no menos de 1500 m2, con todos los servicios subterráneos.

(8) Se trata de un mecanismo de financiamiento de obras para la comunidad por parte de empresas privadas, a cambio de la aprobación de proyectos de construcción o urbanización, en 
condiciones de excepcionalidad respecto de las normas vigentes. Este mecanismo para el desarrollo urbano es nuevo en Argentina y ha sido aplicado solo por Rosario y Córdoba.

(9) Ejemplos de ello son la prolongación de la avenida Cruz Roja Argentina, a cargo de Edisur, o la avenida García Martínez, a cargo de Siragusa y Scolari/Flores.

\section{Bibliografía}

Améndola, G. (2000). La ciudad postmoderna: magia y miedo de la metrópolis contemporánea. Madrid: Caeleste.

Barreto, M. Á. (1995). La renta del suelo y sus efectos espaciales. En Cuaderno 2. Recuperado de file:///C:/Users/Cecilia/Downloads/2052-5933-1-PB\%20(2).pdf

Cámara Empresarial de Desarrollistas Urbanos de Córdoba (CEDUC). (17/11/2014). Índice de Ventas de Inmuebles en Córdoba. Recuperado de https://bit.ly/2/Y744X

Capdeville, J. (2013). Cambios y continuidades de los grupos "desarrollistas" y su incidencia en la ciudad de Córdoba. VII Jornadas Santiago Wallace de Investigación en Antropología Social. Buenos Aires: Universidad de Buenos Aires, Facultad de Filosofía y Letras.

Cuenya, B. E. y Corral, M. (2011). Empresarialismo, economía del suelo y grandes proyectos urbanos: el modelo de Puerto Madero en Buenos Aires. EURE (Santiago), 37(111), 2545.

Del Cueto, C. M. y Neuburger, S. (2009). Un country en la ciudad. Reconversión urbana y segregación socio espacial en Buenos Aires. XXVII Congreso de la Asociación Latinoamericana de Sociología, Buenos Aires.

Ferrero, M.; Ibáñez Mestre, G. y Machado Ibars, M. (2012). A la sombra de un modelo económico, el caso de la minería en Córdoba. En Ciuffolini, M. A. (Comp.). Por el oro y el moro. Explotación minera y resistencias en Catamarca, Córdoba y La Rioja (pp. 97119). Córdoba: El Colectivo.Gobierno de la provincia de Córdoba (2008). Censo Provincial 2008. Recuperado de https://bit.ly/2|x6Tgl Grupo Edisur (2008). Revista Cálamo, 2(10).

Harvey, D. (2007). Espacios del capital: hacia una geografía crítica. Madrid: Akal.

Municipalidad de Córdoba (1993). Ordenanza municipal 8606/91. Recuperado de https://bit.ly/2IAxdXa

Municipalidad de Córdoba (2008). Plan Director 2020 Córdoba. Recuperado de http://sistemamid.com/preview.php?a=96872

Núñez, A. (2013). Territorialidades itinerantes. Apropiación y expropiación de territorialidades 
sociales en ciudades argentinas. Buenos Aires: Universidad Nacional del Mar del Plata.

Roitman, S. (2003). Barrios cerrados y segregación social urbana. Scritpa Nova, 8(146).

Saccucci, E. y Feldmann, N. (2015). En los márgenes del margen El suelo de la periferia, entre la dominación y la resistencia. Studia Politicæ, 30, 83-107.

Stratta, F. y Barrera, M. (2009). El tizón encendido. Protesta social, conflicto y territorio en la Argentina de la posdictadura. Buenos Aires: El Colectivo.

Tabakman, D. (2006). Desarrollos inmobiliarios exitosos. Buenos Aires: Ediciones BRE.

\section{Otras fuentes}

El Llano en Llamas (mayo de 2013). Tomas de tierras en Córdoba. Córdoba, Argentina. Recuperado dehttps://bit.ly/2ktcu7F

Día a día (23 de febrero de 2015). Costa canal: una villa quebrada. Recuperado de http://www.diaadia.com.ar/cordoba/costa-canal-una-villa-quebrada

La Voz del Interior (9/12/2018). ¿Qué clase de negocios son los convenios urbanísticos? Recuperado de https://www.lavoz.com.ar/ciudadanos/que-clase-de-negocios-sonconvenios-urbanisticos

La Voz del Interior (11/12/2018). En 2019, Edisur prevé crecer 50\% real y planea más inversión. Recuperado de https://www.lavoz.com.ar/negocios/en-2019-edisur-preve-crecer-50real-y-planea-mas-inversion

La Voz del Interior (12/09/2018). Edisur finalizó las primeras tres casonas construidas junto a inversores. Recuperado de https://www.lavoz.com.ar/negocios/edisur-finalizo-primerastres-casonas-construidas-junto-inversores

La Voz del Interior (16/02/2012). Regularán excepciones para desarrollistas. Recuperado de https://www.lavoz.com.ar/cordoba/regularan-excepciones-para-desarrollistas

La Voz del Interior (19/09/2008). La concertación con Edisur incluirá dos dispensarios. Recuperado de archivo.lavoz.com.ar/nota.asp?nota_id=241597

La Voz del Interior (21/10/2014). La venta de lotes compensó la caída de departamentos y cocheras. Recuperado de www.lavoz.com.ar/negocios/la-venta-de-lotes-compenso-lacaida-de-departamentos-y-cocheras2013 
La Voz del Interior (24/02/2013). Tierra cada vez más cara y escasa. Recuperado de https://www.lavoz.com.ar/cordoba/tierra-cada-vez-mas-cara-escasa

La Voz del Interior (27/10/2014). Habría menos expensas para "countries". Recuperado de http://www.lavoz.com.ar/ciudadanos/habria-menos-expensas-para-countries 